\author{
Мартыновский В.C. \\ кандидат экономических наук, доцент \\ E-mail: martinv@i.ua \\ Кулаковская Т.A. \\ кандидат экономических наук, доцент \\ кафедра экономики промышленности \\ E-mail: tatyana_kula@mail.ru \\ Фарзетдинов Д.Ф. \\ Студент 4 курса фракультета экономики бизнеса и контроля \\ Одесская национальная академия пищевых технологий \\ ул. Канатная, 112, м. Одеса, Украина, 65039 \\ E-mail: farzetdinovd@gmail.com
}

\title{
ПРОБЛЕМЫ НАЛОГОВОЙ СИСТЕМЫ УКРАИНЫ
}

В данной статье рассмотрены проблемы налоговой системы Украины и высоких ставок налогов, что приводит к увеличению доли теневой экономики. Рассмотрены налог на добавленную стоимость и налог на доходы фризических лиц. Также были описаны методы по оптимизации налоговой системы.

Ключевые слова: налоговая система; экономика; государственный бюджет; налог на добавленную стоимость.

This work is licensed under a Creative Commons Attribution 4.0 International License http://creativecommons.org/licenses/by/4.0/

Постановка проблемы и ее связь с важными научными и практическими задачами. Налоговая система является инструментом развития хозяйственной деятельности любой страны. Неэффективность налоговой политики приводит к увеличению количества убыточных предприятий, росту «теневой экономики», предвзятое негативное мнение общества к самому понятию «налоги» (рис.1).

Как видно на рис. 1, одним из основных факторов, который сдерживает поступление инвестиций и мешает ведению иностранного бизнеса в Украине, является несовершенство налоговой системы (95\%).

Анализ последних публикаций по проблеме. Проблемы налоговой системы рассматривали: Р.В.Тульчинский, М.П. Кучерявенко, О.Д. Василик, Ярошенко Ф.О., В.М.Федосов, однако тема все еще остается актуальной.

Формулирование целей исследования. Целью статьи является выявление недостатков налоговой системы Украины и рассмотрение методов их устранения.

Изложение основных результатов и их обоснование. Налоговая система представляет собой свод правил по уплате налогов юридическими и физическими лицами и, таким образом, влияет на формирование бюджетов на различных уровнях хозяйствования. Так же, как и в других странах, налоги подразделяются на общегосударственные и местные налоги и сборы.

Можно отметить основные недостатки налоговой системы Украины: тельства;

нестабильность налогового законода-

- сложность учета и уплаты налогов в соответствующие органы субъектами хозяйствования; - сформированные многочисленные внебюджетные фонды целевого назначения, что усложняет уплату налогов и контроль над их осуществлением;

- политика исполнительной власти, направлена исключительно на пополнение бюджета любой ценой, и это заставляет плательщиков налогов уклоняться от их уплаты, таким образом, этот фактор способствует сокрытию части налогов, что и приводит к появлению теневой экономики.

Исходя из вышеперечисленного, можно сделать вывод, что главная нацеленность налоговых органов, направленная на запланированный объем штрафов позволяет налогоплательщикам порой рассчитывать на то, что достаточно договориться с контролерами об успешном прохождении налоговой проверки. В результате виновность субъекта хозяйствования уходит на задний план, а соблюдение законодательства вообще становится не главным.

К общегосударственным налогам, в первую очередь, относится налог на прибыль предприятия. В 2015 году он составил 32,5 млрд грн, что на 23\% меньше налога на доходы физических лиц (39,9 млрд грн) и меньше 7\% от общей суммы в бюджете, от поступивших доходов. 


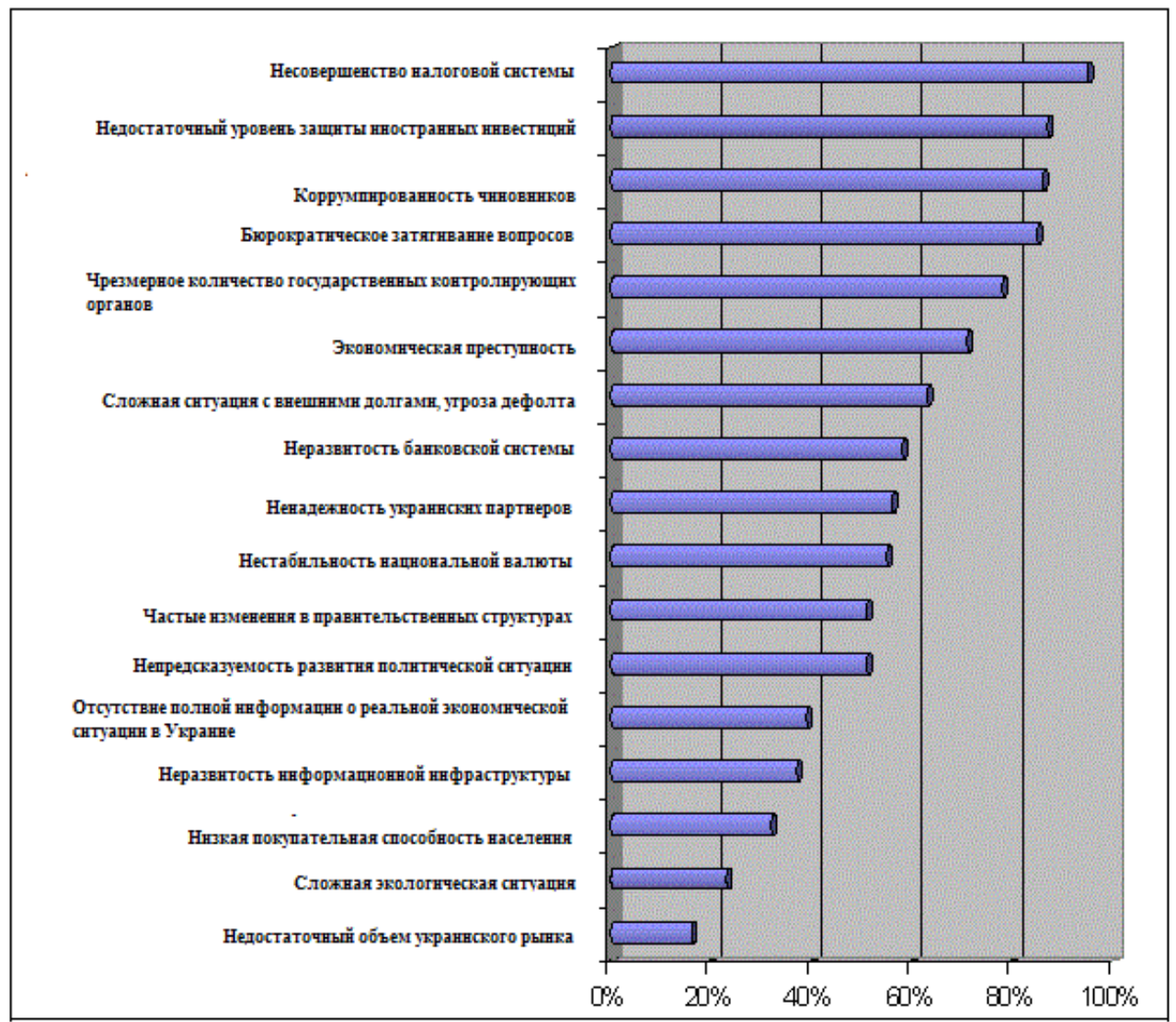

Рис.1. Факторы, негативно влияющие на ведение иностранного бизнеса в Украине, \% опрошенных [7]

Исходя из приведенных данных, предприниматели хорошо усвоили, как искусственно увеличить расходы, тем самым уменьшая величину показываемой прибыли.

В Украине, на первый взгляд, одна из самых низких налоговых ставок на доходы физических лиц, которая составляет на сегодня $18 \%$. Сравнение со странами Евросоюза выглядят следующим образом: налог на доходы физических лиц в Польше - 32\%, Германии $-45 \%$, Австрии - 50\%. Но если учесть, что в этих и многих других экономически развитых странах юридические лица не выплачивают взносы в пенсионный фонд и фонд социального страхования, то можно считать, что в Украине налог на доходы физических лиц составляет не менее 50\% [5]. Несмотря на такую высокую ставку налога, постоянно существует проблема с дефицитом средств в государственном бюджете. На практике такой налог стимулирует оплату «черной» зарплаты, из-за чего в бюджет поступает минимальная часть от этих выплат. Только понижение налогов может мотивировать предпринимателей платить «белую» зарплату.

Также стоит рассмотреть налог на добавленную стоимость, который составляет более $30 \%$ государственного бюджета. В Украине НДС удерживается по ставке в 20\%, в России - $18 \%$, в Казахстане $12 \%$, в Южной Корее - 10\%, в Тайване $5 \%$, в Швеции и Норвегии - 25\%, в Польше и
Румынии - 23\% [4]. Этот налог формирует государственный бюджет страны в большей степени, чем какой-либо другой, однако, в Украине очень остро стоит проблема его невозврата, так как чем выше ставка этого налога, тем больше проблема его возмещения. Снижение налоговой ставки на добавленную стоимость позволит снизить цены на розничные товары внутри страны, что, возможно, сделает проблемы фиктивного налога на добавленную стоимость менее ощутимыми, так как компаниям заплатить их будет менее проблематично, чем производить махинации с этим налогом - это одна из причин, почему высокие налоги результат того, что большая часть деятельности находится в оффшорных зонах.

Кроме указанных, существуют и странные налоги, например, экологический налог. Уже много лет обсуждается его совершенствование, но никаких изменений не происходит. Любому предпринимателю выгоднее регулярно оплачивать этот налог вместо того, чтобы вложить средства в проведение мероприятия по организации здоровой экологической ситуации в районе, где функционируют его предприятия. Причиной является ставка экологического налога.

Но, как уже указывалось, налоговая система представляет собой мощный двигатель развития хозяйственной системы. Для развития хозяйственной 
системы, без которого не будет осуществляться общее развитие, необходимо ускоренное обновление производственного аппарата. Для этого необходимы перманентные инновации, которые должны обеспечиваться инвестиционными средствами, которые и должна дать налоговая система наряду с другими источниками инвестирования, и эта задача является одной из важнейших при покрытии расходов бюджета.

Это возможно только через централизованное управление государственным законодательством через соответствующие органы. Если же проанализи- ровать данные поступлений средств из государственного бюджета за 2009 год, то можно увидеть, что капитальные расходы составляли 11,4 млрд. грн., что равнялось $2,36 \%$, а расходы на приобретение основного капитала и того меньше 7,8 млрд. грн.

Это подтверждает статистика капитальных расходов государственного бюджета (средства, направленные на обеспечение инновационного и инвестиционного видов деятельности) за 2012-2014 гг. (табл.1).

Таблица 1

Капитальные расходы государственного бюджета за 2012-2014 гг.[8]

\begin{tabular}{|c|c|c|c|c|c|}
\hline \multicolumn{2}{|c|}{2012 год, млрд. грн. } & \multicolumn{2}{|c|}{2013 год, млрд. грн. } & \multicolumn{2}{|c|}{2014 год, млрд. грн. } \\
\hline План & Факт & План & Факт & План & Факт \\
\hline 45 & 29,5 & 29,6 & 17,8 & 14,8 & 7,4 \\
\hline
\end{tabular}

Данные, приведенные в табл. 1, свидетельствуют о том, что капитальные бюджетные расходы неуклонно снижаются, и о государственном инвестировании не может быть и речи. Это подтверждает и структура капитальных инвестиций за январь-сентябрь 2015 года (табл. 2).

Капитальные инвестиции по источникам финансирования за январь-сентябрь 2015 г. [1, 2]

Таблица 2

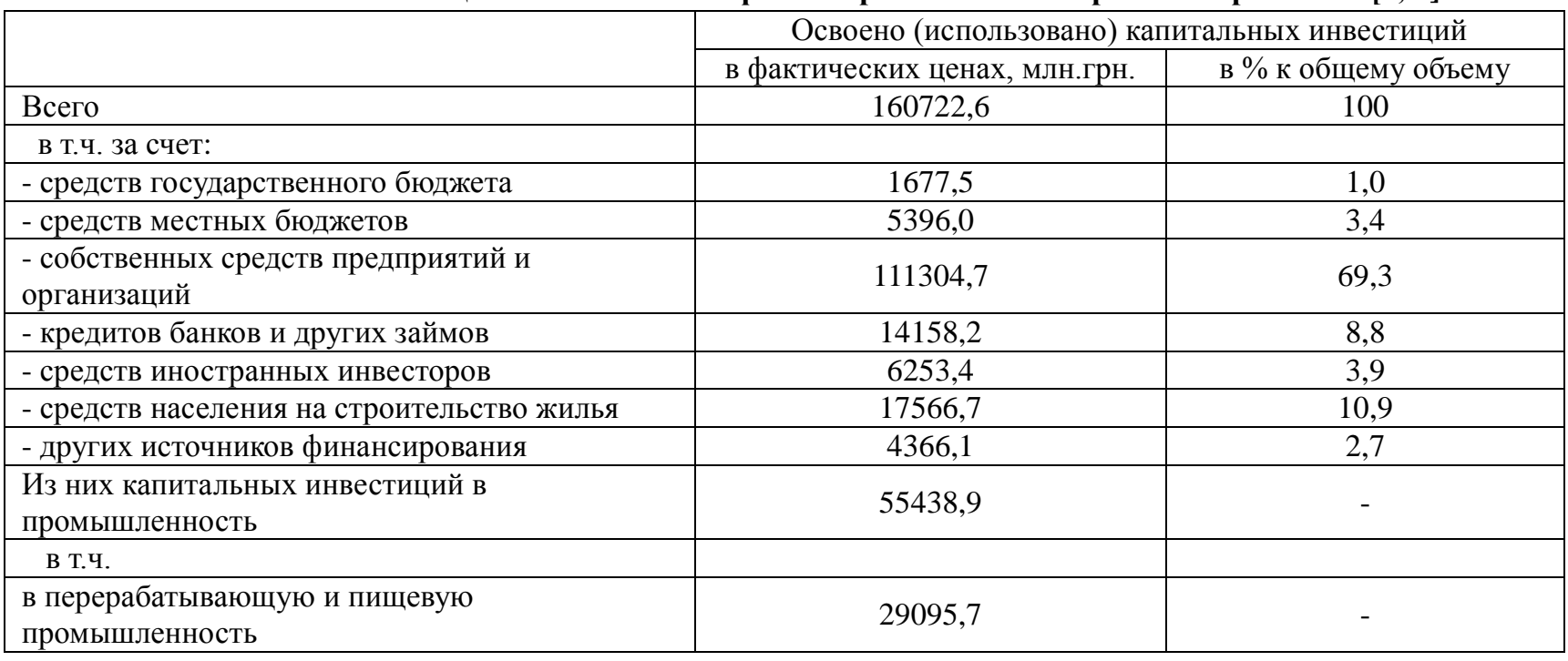

Одним из путей решения проблемы является инвестирование деятельности за счет собственных средств. Однако такое положение может измениться в любой момент, в зависимости от политической, социальной, финансовой ситуации.

Для увеличения притока средств на инвестирование и, соответственно, внедрение инноваций предприятиям разрешено применять ускоренную амортизацию. Но предприятия оказываются как бы разделенными на две группы: государственные и частные. При этом ускоренная амортизация ими не применяется. Частные предприятия, в силу несовершенства систем учета, некомпетентности и нежелания сотрудников и незаинтересованности предпринимателей и специалистов, а для государственных установлен лимит сроков полезного использования элементов основных средств, по-видимому, для определения минимального размера прибыли и уплаты налога в бюджет.

Не говоря о пассивной части, срок использования машин и оборудования установлен на минимальном уровне в 5 лет, для электронновычислительной техники в 2 года, для инструментов, приборов инвентаря 4 года. С такими темпами не приходится рассчитывать на достижение технического и технологического уровня развития стран, где обновление основного капитала осуществляется в 1,5-2 раза быстрее.

Выводы и перспективы дальнейших исследований. В ходе исследования были выявлены основные недостатки налоговой системы Украины, 
которые сдерживают развитие предпринимательства и стимулируют рост доли «теневой» экономики. Эти проблемы должны решаться налоговой системой. Необходимо пересмотреть налоговую систему и включить в нее льготы в первую очередь для тех предприятий, которые используют средства на вне- дрение инноваций. Она должна быть гибкой и адаптироваться к меняющейся хозяйственной деятельности. По мнению авторов, также необходимо обеспечить защиту прав и интересов налогоплательщиков и ввести понятие непреднамеренного нарушения налогового законодательства.

\section{Література}

1. Капитальные инвестиции по видам промышленной деятельности за 2015 год [Електронный ресурс] // Ukrstat.org - публикация документов Государственной Службы Статистики Украины. - 2015. - Режим доступа : https://ukrstat.org/operativ/operativ2015/ibd/iki_pr/iki_pr_r/kipr_15_r.htm. Ukrstat.org.

2. Капитальные инвестиции по источникам финансирования за январь - сентябрь 2015 года [Електронный pecypc] // Ukrstat.org - публикация документов Государственной Службы Статистики Украины. - 2015. - Режим доступа : https://ukrstat.org/operativ/operativ2015/ibd/kindj/infin_r/infin03_15_r.html

3. Податковий кодекс України [Електронний ресурс] // Офіцийний портал державної фіскальної служби України. - Режим доступу до ресурсу : http://sfs.gov.ua/nk/spisok3/

4. Корнус В. Оценка налоговой нагрузки на уровне предприятия / В.Корнус, В.Квасов, А.Пономарев // Экономист. - 2007. - С.47-49

5. Налоговая политика Украины: состояние, проблемы, перспективы [монография ] / [П.В. Мельник, Л.Л. Тарангул, 3.С. Варналий и др., под ред. 3.С. Варналия]. - К.: Знание Украины, 2008. - 657 с.

6. Саварина А. Совершенствование законодательства по вопросам налогообложения субъектов предпринимательской деятельности / А. Саварина // Право Украины. -2009. - № 7. - С. 46-49.

7. Инвестиционно-предпринимательский климат в Украине, оценки западных экспертов [Електронний ресурс] // Центр Разумкова. - Режим доступу до ресурсу :

http://www.razumkov.org.ua/ukr/article.php?news_id=65.11.

8. Доходы госбюджета Украины 2015 [Електронний ресурс] // Финансовый портал «МИНФИН». - 2015. Режим доступу : http://index.minfin.com.ua/budget/income/?2015.

9. Податкова система України, ії недоліки та шляхи реформування [Електронний ресурс] // НТУУ «КПІ». - 2009. - Режим доступу : http://ela.kpi.ua/handle/123456789/6433.

Мартиновський В.C.

кандидат економічних наук, доцент

E-mail: martinv@i.ua

Кулаковська Т.A.

кандидат економічних наук, доцент кафедра економіки промисловості

E-mail: tatyanakula@mail.ru

Фарзетдінов Д.Ф.

Студент 4 курсу фракультету економіки, бізнесу і контролю

Одеська національна академія харчових технологій

вул. Канатна, 112, м. Одеса, Україна, 65039

E-mail: farzetdinovd@gmail.com

\section{ПРОБЛЕМИ ПОДАТКОВОЇ СИСТЕМИ УКРАЇНИ}

Податкам відведене одне з найважливіших економічних важелів, якими держава впливає на ринкову економіку. Податки є потужним інструментом управління економікою, як і вся податкова система.

У сучасних умовах, в Україні дуже важлива ефективна оптимізація оподаткування юридичних і фрізичних осіб, так як неоптимальні розміри податкових ставок є основною причиною ведення «чорної» бухгалтерії і відходу підприємств в «тіньову» економіку. Тому так важливо дотримуватися таких основних принципів оподаткування, як стимулювання підприємницької, інноваційної, інвестиційної діяльності, а також забезпечити умови для добровільного виконання податкових зобов'язань та 
поступового зниження податкового навантаження для платників податків.

У статті представлено порівняння податкових ставок України з розвиненими країнами і проблема дефіциту коштів в державному бюджеті. Також розглядається недосконалість амортизаційної політики щодо інших розвинених країн, яка обмежує підприємців в прирості грошового потоку шляхом оновлення основних засобів, який може бути направлений на подальші інвестиції в підприємство.

Ключові слова: податкова система; економіка; державний бюджет; податок на додану вартість.

\section{Martynovsky V.}

Ph.D. in Economics, Associate Professor

E-mail: martinv@i.ua

Kulakovskaya T.

Ph.D. in Economics, Associate Professor

Department of Industrial Economics

E-mail: tatyana_kula@mail.ru

Farzetdinov D.

The student of the fourth grade of Faculty of Economy, Business and Control

Odessa National Academy of Food Technologies

Kanatna str., 112, Odessa, Ukraine, 65039

E-mail: farzetdinovd@gmail.com

\section{PROBLEMS OF THE TAX SYSTEM OF UKRAINE}

Taxes had one of the most important economic levers which the state affects to a market economy. Taxes are a powerful tool for managing the economy, as well as the whole tax system.

Under current conditions it is very important to optimize the effective taxation of businesses and individuals in Ukraine, as non-optimal size of the tax rates is the main reason for doing accounting fraud and exist enterprises in the "shadow" economy. Therefore, it is important to follow basic principles of taxation, such as the promotion of entrepreneurship, innovation, investment, and ensure conditions for voluntary fulfillment of tax obligations and the gradual reduction of the tax burden for the tax payers.

In the article compares the Ukrainian tax rates with developed countries and the problem of shortage of funds in the state budget are represented. Also imperfect of depreciation of policy is considered relative to other developed countries, which limits the growth in business cash flow by updating the fixed assets, which could be guided to further investment of the company.

Key words: tax system; the economy; the state budget; VAT.

\section{References}

1. Kapytalnыe ynvestytsyy po vydam prombshlennoi deiatelnosty za 2015 hod. (2015). Retrieved 2016, from https://ukrstat.org/operativ/operativ2015/ibd/iki_pr/iki_pr_r/kipr_15_r.htm. Ukrstat.org.

2. Kapytalnыe ynvestytsyy po ystochnykam fynansyrovanyia za yanvar - sentiabr 2015 hoda. (2015). Retrieved 2016, from https://ukrstat.org/operativ/operativ2015/ibd/kindj/infin_r/infin03_15_r.html

3. Podatkovyi kodeks Ukrainy. (2016). Retrieved 2016, from http://sfs.gov.ua/nk/spisok3/

4. Kornus, V., Kvasov, V., \& Ponomarev, A. (2007). Otsenka nalohovoi nahruzky na urovne predpryiatyia. Эkonomyst, 47-49.

5. Melnyk, P. V., Taranhul, L. L., \& Varnalyi, Z. S. (2008). Nalohovaia polytyka Ukraynы: Sostoianye, problemы, perspektyvы [monohrafyia ]. K.: Znanye Ukraynы.

6. Savaryna, A. (2009). Sovershenstvovanye zakonodatelstva po voprosam nalohooblozhenyia subъektov predprynymatelskoi deiatelnosty. Pravo Ukraynы, 7, 46-49.

7. Ynvestytsyonno-predprynymatelskyi klymat v Ukrayne, otsenky zapadnыkh эkspertov. (2015). Retrieved 2016, from http://www.razumkov.org.ua/ukr/article.php?news_id=65.1

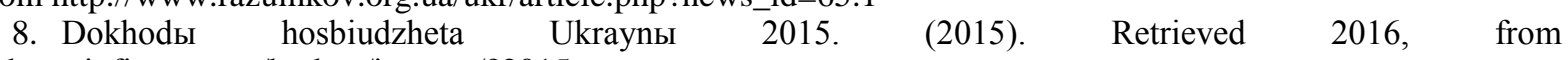
http://index.minfin.com.ua/budget/income/?2015.

9. Podatkova systema Ukrainy, yii nedoliky ta shliakhy reformuvannia. (2009). Retrieved 2016, from http://ela.kpi.ua/handle/123456789/6433 